\title{
Revisiting Formability and Failure of AISI304 Sheets in SPIF: Experimental Approach and Numerical Validation
}

\author{
Gabriel Centeno $^{1, *}$ (1) , Andrés Jesús Martínez-Donaire ${ }^{1}$ (1), Isabel Bagudanch ${ }^{2}$ (1), \\ Domingo Morales-Palma $^{1}$ (D), María Luisa Garcia-Romeu ${ }^{2}$ (D) and Carpóforo Vallellano ${ }^{1}$ \\ 1 Department of Mechanical and Manufacturing Engineering, School of Engineering, University of Seville, \\ 41092 Seville, Spain; ajmd@us.es (A.J.M.-D.); dmpalma@us.es (D.M.-P.); carpofor@us.es (C.V.) \\ 2 Department of Mechanical Engineering and Industrial Construction, University of Girona, 17071 Girona, \\ Spain; isabel.bagudanch@udg.edu (I.B.); mluisa.gromeu@udg.edu (M.L.G.-R.) \\ * Correspondence: gaceba@us.es; Tel.: +34-954-485965
}

Received: 11 October 2017; Accepted: 24 November 2017; Published: 28 November 2017

\begin{abstract}
Single Point Incremental Forming (SPIF) is a flexible and economic manufacturing process with a strong potential for manufacturing small and medium batches of highly customized parts. Formability and failure in SPIF have been intensively discussed in recent years, especially because this process allows stable plastic deformation well above the conventional forming limits, as this enhanced formability is only achievable within a certain range of process parameters depending on the material type. This paper analyzes formability and failure of AISI304-H111 sheets deformed by SPIF compared to conventional testing conditions (including Nakazima and stretch-bending tests). With this purpose, experimental tests in SPIF and stretch-bending were carried out and a numerical model of SPIF is performed. The results allow the authors to establish the following contributions regarding SPIF: (i) the setting of the limits of the formability enhancement when small tool diameters are used, (ii) the evolution of the crack when failure is attained and (iii) the determination of the conditions upon which necking is suppressed, leading directly to ductile fracture in SPIF.
\end{abstract}

Keywords: formability; failure; sheet metal forming; Single-Point Incremental Forming (SPIF)

\section{Introduction}

Incremental Sheet Forming (ISF) processes accomplish the current requirements for rapid, adaptive, economic and environmentally friendly manufacturing. It is especially viable for small batches of parts made of sheet and does not need expensive dedicated machines or equipment. Indeed, it is a relative novel process that has been in the spotlight of the metal-forming community for the last two decades. Although the incremental sheet-forming technology is linked to the process of spinning, the current ISF process has its origins in the late 1960s related to the pioneer works of Leszak [1] and Berghahn and Murray [2], both in 1967. Nevertheless, following the analysis of the historical review by Emmens et al. [3] only the latter can be regarded as an actual version of modern ISF. This investigation reveals that those 2 initial patents were not the work leading to the present developments, but the Bachelor Thesis of Mason in 1978 [4] presented to the scientific community later in 1984 [5], which would be the real origin of the current state of the art in ISF.

Single-Point Incremental Forming (SPIF) is the simplest type within ISF processes, which make use of a simple setup not requiring any partial or full die. As shown in Figure 1, the SPIF technology consists of a hemispherical end-forming tool driven by a CNC machine that follows progressively a pre-established trajectory, deforming a peripherally clamped sheet blank into a final component without the use of any specific forming die. 


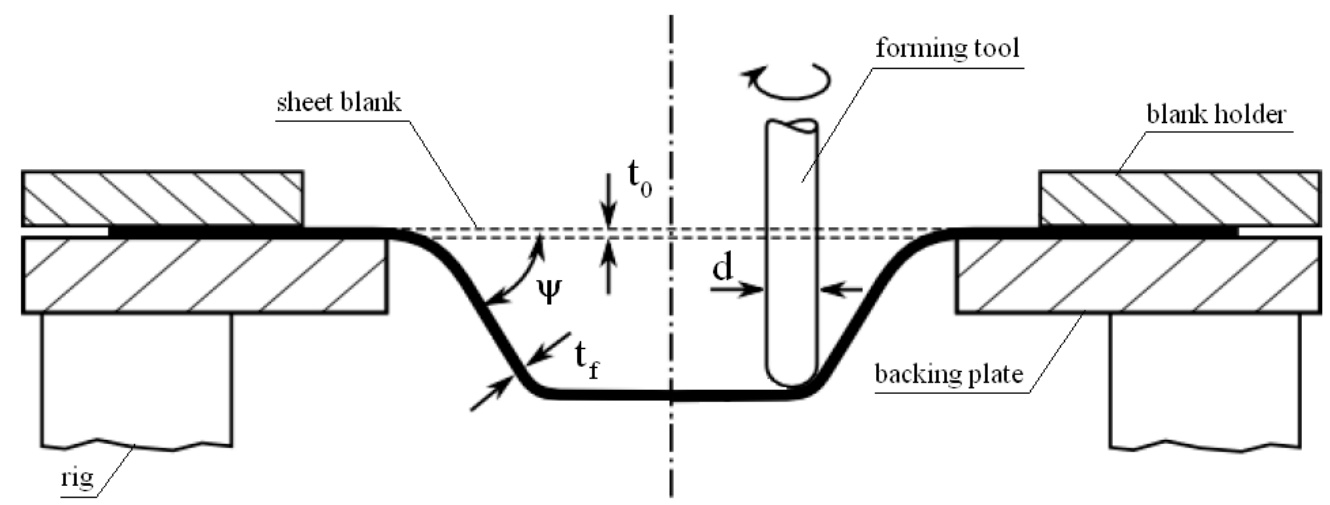

(a)

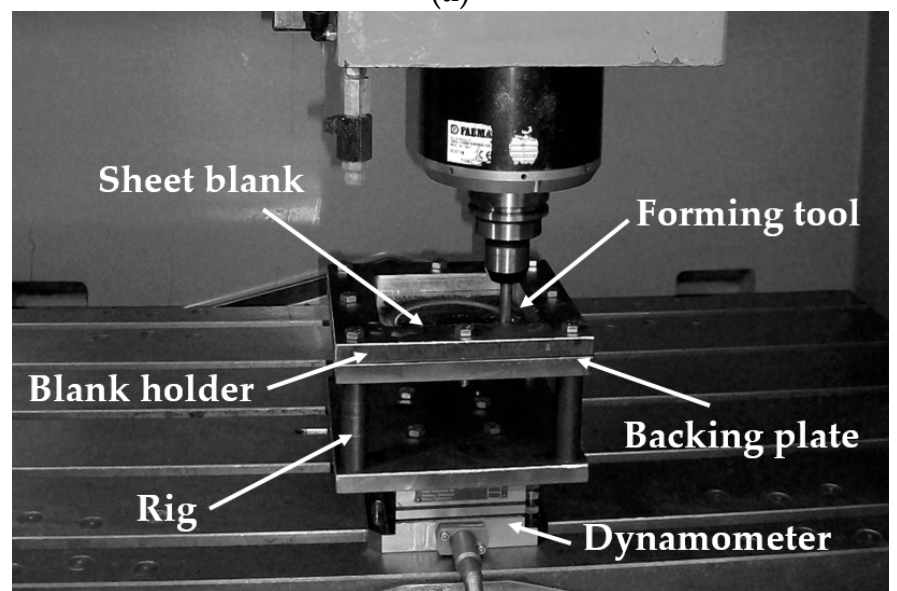

(b)

Figure 1. (a) Schematic representation of the SPIF process and (b) experimental setup utilized.

Formability and failure of sheet metal deformed by SPIF is usually analyzed within Forming Limit Diagrams or FLDs, which include the limit strains at the onset of local necking, represented by the Forming Limit Curve (FLC), as well as at ductile fracture, characterized by the Fracture Forming Line (FFL). The current methods for the evaluation of these limit strains at the onset of necking and fracture have been recently discussed in [6]. In this regard, high ductility metal sheets deformed by conventional forming processes usually start failing at the onset of necking, i.e., the material deforms continuously within this neck under an unstable deformation process, following approximately a near plane strain state, until the ductile fracture takes place. On the contrary, metal sheets deformed by SPIF (or any other ISF variety) within a certain range of process parameters suffer a stable straining above the FLC that may lead directly to ductile fracture. The stabilization mechanisms providing the enhanced formability observed in ISF are presented and discussed in the review paper by Emmens and van den Boogaard [7].

With this background, Silva et al. [8] carried out tests that revealed the possible existence of both deformation mechanisms, either fracture with a previous necking or failure by direct ductile fracture, depending on the ratio between the initial thickness of the sheet and the radius of the tool $\left(t_{0} / R\right)$. For large tool diameters, failure by necking could still occur, whereas for small tool diameters, fracture in absence of necking would be promoted, and formability should then be represented by the FFL. A more recent study [9] demonstrated that in both of the previous cases, i.e., failure controlled either by necking or by ductile fracture, fracture strains are always within a scatter band of the FFL.

In this regard, the authors studied in a previous work [10] the effect of the localized bending induced by the forming tool, evaluated through the above mentioned $\mathrm{t}_{0} / \mathrm{R}$ ratio, in the stabilization of plastic deformation above the FLC during ISF. It was observed that for higher tool diameter $(20 \mathrm{~mm})$, 
the failure mode was due to necking followed by ductile fracture. However for the lowest tool diameters considered $(10 \mathrm{~mm})$, failure occurred by fracture in the absence of necking.

Furthermore, considering that for a certain range of process parameters corresponding to high $t_{0} / \mathrm{R}$ ratios failure will occur without previous necking in SPIF, Isik et al. [11] proposed a new methodology to determine the maximum strains at fracture directly from the in-plane strain measurements without evaluating the gauge length strains, which simplifies the procedure for obtaining the FFL. What is required is a series of tests on parts with a variable wall angle: truncated conical parts (plane strain conditions) and truncated pyramidal parts (plane strain conditions in the walls of the pyramid and biaxial stretching at the corners). Isik et al. also introduced the concept of Shear Fracture Forming Limit line or SFFL, corresponding to mode II of the fracture mechanics (in-plane shear), which can also be excited under certain loading conditions in ISF. In-plane torsion tests and plane shear tests are required to represent this new forming limit. In order to simplify and facilitate the determination of SFFL, a new geometry manufactured by ISF has been recently proposed [12]. This proposal involves using a truncated lobe conical shape with varying wall angle and measuring the in-plane strains at fracture, thus avoiding the need to measure gauge length strains, which is required with typical test specimens (in-plane torsion and plane shear tests).

In this scientific framework for SPIF, this paper allows the authors presenting the following contributions to the current state of the art in ISF regarding the SPIF process applied to AISI304-H111 sheets: (i) the setting of the limits of the formability enhancement when small tool diameters are used, (ii) the evolution of the crack when failure is attained and (iii) the conditions, validated by the FEA, upon which necking is suppressed, leading directly to ductile fracture in SPIF.

After contextualizing this study within the state of the art in SPIF, Section 2 presents the material and experimental methods utilized, Section 3 focuses on the numerical modelling of the SPIF process carried out and Section 4 discusses the experimental and numerical results obtained. Finally, the contributions of the paper are exposed in Section 5 "Conclusions".

\section{Materials and Experimental Methods}

This section starts presenting the mechanical characterization of the AISI304-H111 metal sheets obtained from uniaxial tensile tests and providing a power law containing the plastic behavior of the material to be used in the numerical simulations.

In Section 2.2, the forming limits of the material are given by means of conventional Nakazima tests, which combined by a series of stretch-bending tests carried out with a set of cylindrical punches provide the FLD of the sheet metal including bending effects.

Finally, the experimental plan and the experimental methods used in the case of the SPIF tests are presented in Section 2.3.

\subsection{Mechanical Characterization}

The material analyzed is stainless steel AISI 304-H111 sheet metal of $0.8 \mathrm{~mm}$ thickness. The mechanical properties obtained from the tensile tests are summarized in Table 1 [10]. As pointed out in the cited previous work of the authors [10], the plastic behavior of the material fits a Swift's power law as shown in Equation (1).

$$
\bar{\sigma}=K\left(\varepsilon_{0}+\bar{\varepsilon}^{P}\right)
$$

where $E$ is the elastic modulus, $\sigma_{\mathbf{y} 0.2}$ is the yield stress, UTS the ultimate tensile stress, $K, n$ and $\varepsilon_{0}$ are constants of the Swift's power law depending on the material, $\bar{\varepsilon}^{P}$ is the equivalent plastic strain and $\bar{\sigma}$ the equivalent stress. 
Table 1. Mechanical properties from tensile tests and Swift's power law parameters.

\begin{tabular}{cccccc}
\hline$E(\mathrm{GPa})$ & $\sigma_{\mathrm{y} 0.2}(\mathrm{MPa})$ & UTS $(\mathrm{MPa})$ & $\boldsymbol{K}(\mathrm{GPa})$ & $\boldsymbol{n}$ & $\varepsilon_{\mathbf{0}}$ \\
\hline 207 & 503 & 669 & 1.55 & 0.594 & 0.055 \\
\hline
\end{tabular}

\subsection{Forming Limit Diagram}

A series of Nakazima tests were carried out using a hemispherical punch of $100 \mathrm{~mm}$ diameter using specimens corresponding to uniaxial, close to plane strain and biaxial strain conditions. The conventional forming limits represented by the FLC and the FFL were obtained. In addition, stretch-bending tests using cylindrical punches of $\Phi 20, \Phi 10$ and $\Phi 6 \mathrm{~mm}$ were performed with the aim of evaluating the effect of the bending induced by the tool radius in postponing the onset of necking due to the significant through-thickness strain gradient induced by the curvature of the punches. These former cases led to strain paths in between plane and uniaxial strain. At least 3 replicates of every test were carried out in order to provide statistical meaning to the results obtained.

The tests were performed in a universal sheet metal testing machine Erichsen 142-20 under the testing conditions of the standard ISO 12004-2:2008 [13]. The punch velocity was set to $1 \mathrm{~mm} / \mathrm{s}$ and the lubricant at the interface punch-sheet was Vaseline + PTFE + Vaseline. The system ARAMIS ${ }^{\circledR}$, based on digital image correlation (DIC), was used at a rate of 12 frames per second to evaluate the onset of necking by using a methodology proposed by the authors [14].

Once the onset of necking is attained, the major strain $\left(\varepsilon_{1}\right)$ of the points distributed around the failure zone develops unstably close to plane strain conditions until the fracture strains is reached, being this behavior characteristic in the necking-controlled failure observed in all of the Nakazima and stretch-bending tests. According to this, the procedure for constructing the FFL starts by measuring the thickness at fracture at several places along the crack in order to obtain the average thickness strain, which is evaluated using the measurements at both sides of the crack for every tested specimen. The average minor strain is evaluated along the fracture line at the last image recorded by ARAMIS ${ }^{\circledR}$ before the crack appearance. The major strain is then calculated by volume constancy as expressed in Equation (2).

$$
\bar{\varepsilon}_{1, f}=-\left(\bar{\varepsilon}_{2, f}-\bar{\varepsilon}_{3, f}\right)
$$

where $\bar{\varepsilon}_{2, f}$ and $\bar{\varepsilon}_{3, f}$ are the average minor and thickness strains evaluated in a series of points along the crack line. In addition, it must be pointed out that some tested specimens were cut perpendicularly to the crack and the thickness was measured from a profile view in order to validate the previous thickness measurements along the crack. This methodology for determining the strains at fracture is based on the work of Atkins [15] and has been successfully used by the authors in recent research work for measuring fracture strains in forming of sheet metal [10], polymeric sheets [16,17], or even other processes such as tube-end forming [18].

Figure 2 depicts the forming limit diagram of the AISI 304-H111 sheets including bending effects. The evaluation of the FLC and the FFL was performed by using the methodologies exposed above and only taking into account the Nakazima tests. The average necking and fracture strains are provided for the 3 strain paths considered. As can be seen, the FLC presents the expected V-shape whereas the FFL falls to the first quadrant of principal strain following the straight line $\varepsilon_{1}+0.69 \varepsilon_{2}=1.08$ with a slope not far from the theoretical value of " 1 " proposed by Atkins in [15]. The kink of the strain paths from the onset of necking towards fracture is almost vertical in the first quadrant whereas this transition in the second quadrant suffers from a slight leftward slope, according again to the cited work of Atkins. As can be seen, the bending effect is represented by means of the average necking and fracture strains (not used for obtaining the FLC and FFL) in the stretch-bending tests. Notice that although the significant enhancement of formability attained above the FLC due to this bending effect (which is further discussed in [14]), the fracture strains are placed on the FFL region. 


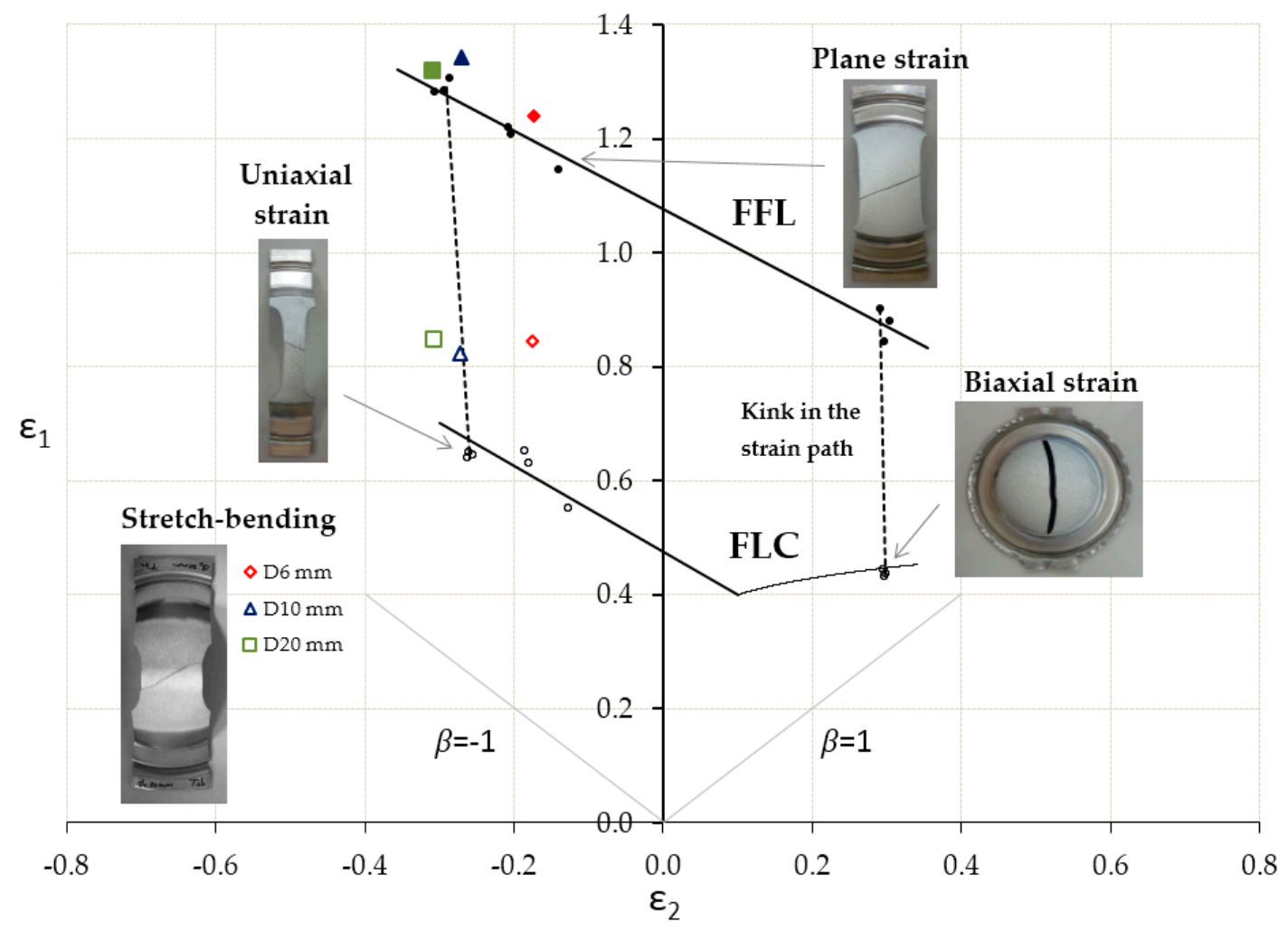

Figure 2. FLD of AISI 304-H111 sheets including bending effects.

\subsection{Single Point Incremental Forming Tests}

A Computer Numeric Control (CNC) 3-axis milling machine Kondia ${ }^{\circledR}$ HS1000 equipped with the experimental setup shown in Figure $1 \mathrm{~b}$ was used for carrying out the SPIF tests. As shown in Figure 3a the testing geometry was a conical frustum with circular generatrix of radius $40 \mathrm{~mm}$, initial diameter of the truncated cone $70 \mathrm{~mm}$, and initial drawing angle $20^{\circ}$. Tool diameters of 20,10 and $6 \mathrm{~mm}$ were utilized. The step down was set alternatively to $0.2 \mathrm{~mm}$ and $0.5 \mathrm{~mm} /$ pass. The step down movement was in the same place during the test, following the forming tool alternatively in-plane clockwise or counterclockwise trajectories for consecutive step downs (see Figure 3b) in order to avoid torsion effects in the final part (see Figure 3c). The tool rotation was free. Special metal-forming lubricant Houghton TD-52 was used with the aim of minimizing friction.

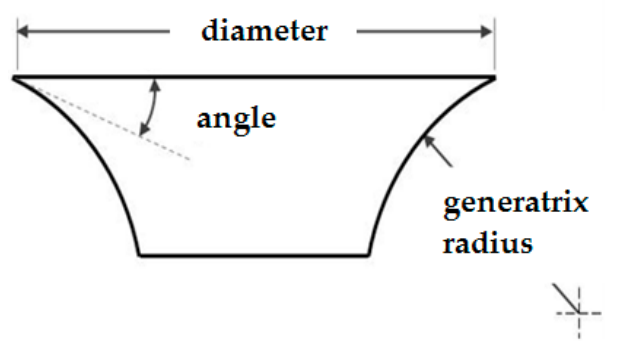

(a)

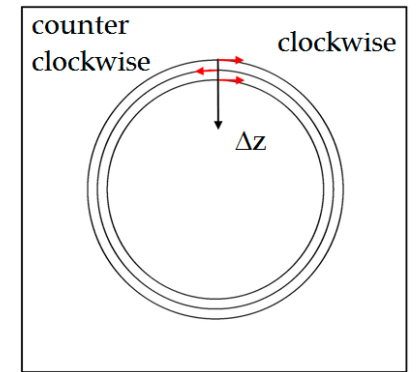

(b)

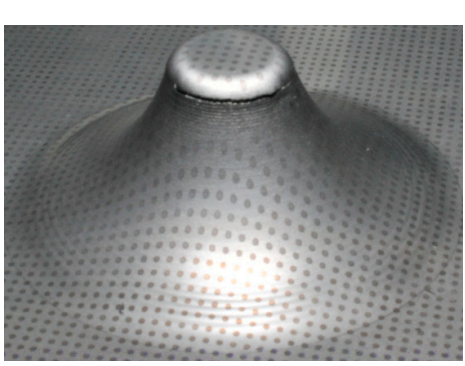

(c)

Figure 3. (a) Truncated coned geometry, (b) tool trajectory and (c) final part after testing.

Table 2 shows the SPIF tests carried out within the experimental plan designed, which was already presented in [10]. Once again, three replicates of every SPIF test were carried to provide statistical meaning to the results obtained. The table provides the final depth recorded in the instant in which 
the failure took place and as well the proportional final forming angle calculated from the predicted trajectories to form the final testing part geometry.

Table 2. Experimental plan of SPIF tests.

\begin{tabular}{cccc}
\hline $\begin{array}{c}\text { Tool Diameter } \boldsymbol{\Phi} \\
(\mathbf{m m})\end{array}$ & $\begin{array}{c}\text { Step Down } \Delta \mathrm{z} \\
(\mathbf{m m} / \text { pass })\end{array}$ & $\begin{array}{c}\text { Final Depth } \mathbf{Z}_{\mathbf{f}} \\
(\mathbf{m m})\end{array}$ & $\begin{array}{c}\text { Final Forming Angle } \boldsymbol{\alpha}_{\mathbf{f}} \\
\left({ }^{\circ}\right)\end{array}$ \\
\hline \multirow{2}{*}{20} & 0.2 & $23.8 / 23.8 / 23.8$ & $69.8 / 69.8 / 69.8$ \\
& 0.5 & $24.5 / 24.0 / 24.0$ & $70.9 / 70.1 / 70.1$ \\
\hline \multirow{2}{*}{10} & 0.2 & $28.0 / 28.2 / 28.2$ & $76.1 / 76.4 / 76.4$ \\
& 0.5 & $27.5 / 28.0 / 28.0$ & $70.9 / 70.1 / 70.1$ \\
\hline \multirow{2}{*}{6} & 0.2 & $28.2 / \mathbf{2 8 . 0 / 2 8 . 8}$ & $76.4 / 76.1 / 77.3$ \\
& 0.5 & $\mathbf{2 8 . 0 / 2 8 . 5 / 2 8 . 0}$ & $76.1 / 76.9 / 76.1$ \\
\hline
\end{tabular}

The final strain state of the testing specimens deformed by SPIF was evaluated off-line by using the 3D deformation digital measurement system ARGUS ${ }^{\circledR}$ based on circle grid analysis. To this aim a grid pattern of $1 \mathrm{~mm}$ diameter was electro-chemically edged on the sheet blank prior to the tests. Figure 4a depicts the grid on the final part deformed by SPIF using a hemispherical forming tool of $20 \mathrm{~mm}$ diameter, whereas Figure $4 \mathrm{~b}$ depicts the contour of the major principal strain evaluated by ARGUS ${ }^{\circledR}$ (notice the similar part orientation in Figure $\left.4 a, b\right)$. The zone of maximum major strain was located at the vicinity of the crack corresponding to the interpolation of the strains throughout it performed by ARGUS ${ }^{\circledR}$. Fracture strains in SPIF were obtained following the methodology that was previously explained in Section 2.2.

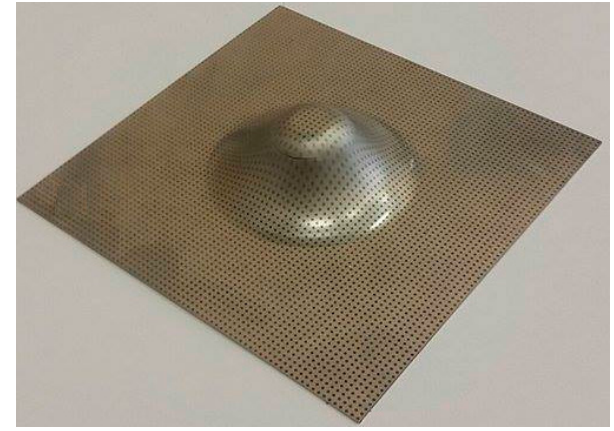

(a)

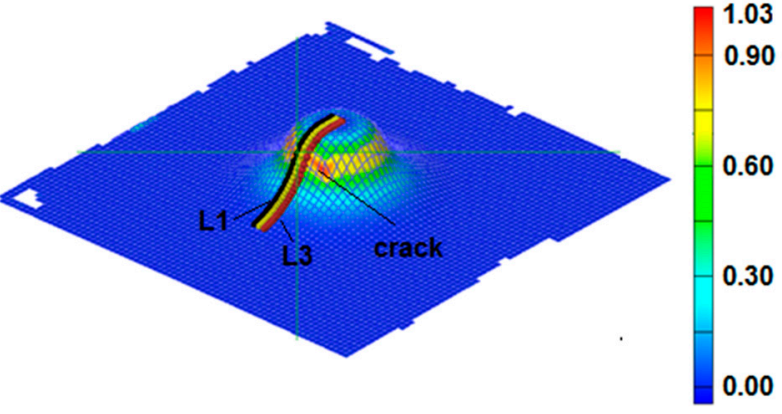

(b)

Figure 4. (a) Final grid and (b) contour of true major principal strain of a tested part by SPIF.

In order to evaluate the principal strains on the outer surface of the final tested parts deformed by SPIF within the FLD of the material, several sections are selected in every case, such as the section L1 to L3 shown in Figure $4 \mathrm{~b}$. The values of the interpolation of principal strains provided by ARGUS ${ }^{\circledR}$ just on the crack line are not taken into account in the FLD, as far as the strains at fracture are calculated using the procedure explained above.

\section{Numerical Modelling}

This section presents the numerical model carried out using DEFORM ${ }^{\mathrm{TM}}-3 \mathrm{D}$ with the aim of analyzing virtually for providing information about the failure prediction and the mechanisms involved in the enhancement of formability attained in SPIF.

DEFORM $^{\mathrm{TM}}-3 \mathrm{D}$ is a commercial Finite Element Analysis (FEA) tool based on flow formulation and with implicit computation. Is it a powerful numerical tool that has been mainly used recently for modelling manufacturing processes such as cutting [19] and bulk forming of metals [20], but it has been also used for simulating sheet metal-forming processes [21,22]. 
The numerical model in DEFORM ${ }^{\mathrm{TM}}-3 \mathrm{D}$ was developed using 3D tetrahedrons, having the initial mesh 50,000 elements. As can be seen in Figure 5a, three circular meshing zones were considered, having the intermediate annulus a smaller size of elements in order to provide accurate results within the tool-sheet contact region corresponding to higher values of major strain. Automatic remeshing was used, allowing DEFORM ${ }^{\mathrm{TM}}-3 \mathrm{D}$ to adapt the mesh size in the zones attaining the highest strain values. The punch is considered to be a rigid body and follows the real trajectory of the experiments. The elements corresponding to the area of sheet metal in contact with the backing plate are considered to be clamped, as shown in Figure 5b. The sheet metal behaves as an elastic-plastic rate-independent material with kinematic hardening. The elastic-plastic behavior is supposed to be isotropic following the Swift's power law presented in Section 2.1. Due to the high computational cost and taking into account the negligible influence of the step down in formability triggered in [10], the step down was set to $0.5 \mathrm{~mm} /$ pass in order to reduce the simulation steps. The simulations were performed until a reference final depth related to the tool depths at failure presented in Table 2, which were chosen to be $24 \mathrm{~mm}$ for the case of a tool diameter of $\Phi 20 \mathrm{~mm}$ and $28 \mathrm{~mm}$ for the case of $\Phi 10 \mathrm{~mm}$ respectively.

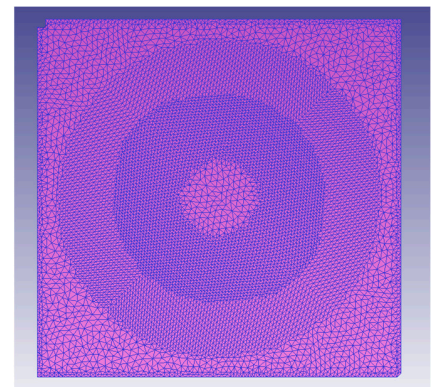

(a)

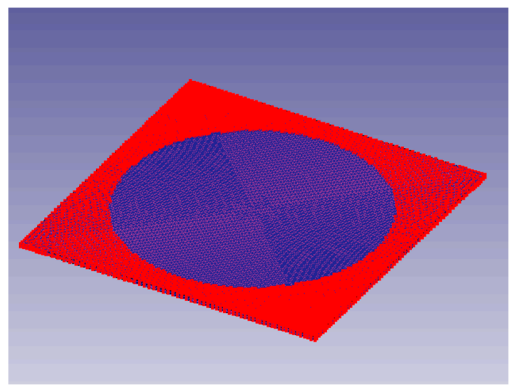

(b)

Figure 5. (a) Meshing zones considered and (b) boundary conditions (clamped condition in "red").

Figure $6 \mathrm{a}, \mathrm{b}$ depicts the deformed shape for the simulation of the SPIF process considering a step down of $0.5 \mathrm{~mm} /$ pass using a tool of $\Phi 20$ and $\Phi 10 \mathrm{~mm}$ respectively. Figure $6 \mathrm{c}$ shows the contour of major principal strains corresponding to the case of a tool of $\Phi 20 \mathrm{~mm}$ (shown in Figure 6a). Notice that in this case, the maximum value of the major strain $\left(\varepsilon_{1}\right)$ provided by the FEA was 0.879 .

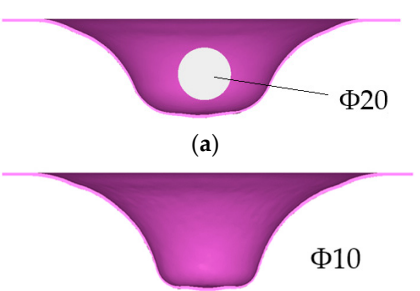

(b)

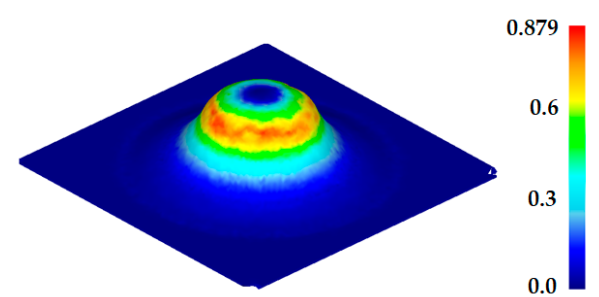

(c)

Figure 6. (a) Deformed shape provided by DEFORM ${ }^{\mathrm{TM}}-3 \mathrm{D}$ of the final testing part in SPIF using a tool of $\Phi 20$ diameter and (b) $\Phi 10 \mathrm{~mm}$. (c) contour of principal strain for the case of $\Phi 20 \mathrm{~mm}$.

Finally, it is worth mentioning that the overall central processing unit (CPU) time for a typical analysis shown in Figure $6 c$, which include 6 remeshing processes, was approximately $85 \mathrm{~h}$ on a laptop using one Intel i7-6500U CPU $(2.60 \mathrm{GHz})$ processor.

\section{Results and Discussion}

In this section, the experimental and numerical results regarding formability and failure of AISI304-H111 sheets deformed in SPIF are presented. In Section 4.1, the limits of the formability enhancement for small tool diameters are evaluated within the FLD of the material. A fractography 
analysis is used to clarify the mode of failure attained, the location where the crack initiates and how it evolves once failure is reached. Section 4.2 discusses the numerical results obtained, presenting the conditions upon which necking is suppressed, leading directly to ductile fracture in SPIF.

\subsection{Experimental Results}

Figure 7 depicts the principal strain state at the outer surface of the final testing part deformed by SPIF using tool diameters of $\Phi 20, \Phi 10$ and $\Phi 6 \mathrm{~mm}$ represented within the FLD of the AISI 304 metal sheets for a step down of $0.5 \mathrm{~mm} /$ pass (as discussed in [10], variations of step down in the range of $0.2-0.5 \mathrm{~mm}$ did not have a relevant influence in formability). Although the three cases show an important enhancement of formability well above the FLC, the increase of formability as well as the mode of failure differs for the different punch radii. In this regard, the transition between the last points of formability provided by ARGUS ${ }^{\circledR}$ and the principal strains at fracture evaluated with the procedure exposed in Section 2.2, is represented in Figure 7 in dotted line. As it was discussed in [10], in the case of a forming tool of $\Phi 20 \mathrm{~mm}$ diameter the failure mechanism was postponed necking followed by ductile fracture, whereas in the case of $\Phi 10 \mathrm{~mm}$, the fractography showed a series of grooves, which has been related to an incipient necking [23]. In this sense, the strain state attained in the case of $\Phi 6 \mathrm{~mm}$ (see Figure 7) almost coincides with the obtained in the case of $\Phi 10 \mathrm{~mm}$. However, in order to evaluate the mode of failure, a fractography analysis is performed. Besides, it must be noticed that the fracture strains in SPIF are slightly above the scatter band of $\pm 10 \%$ with respect to the FFL (which considered only the fracture strains attained in the Nakazima tests). This experimental fact also found in other works $[8,10]$, implies that for some materials Nakazima tests might not be suitable for evaluating the FFL to be used in SPIF. Indeed, the level of triaxiality in stretching (e.g., Nakazima) is much higher than in ISF and then, the ability to reach the fracture limit will depend on the sensitivity of the material to the triaxiality state for fracture.

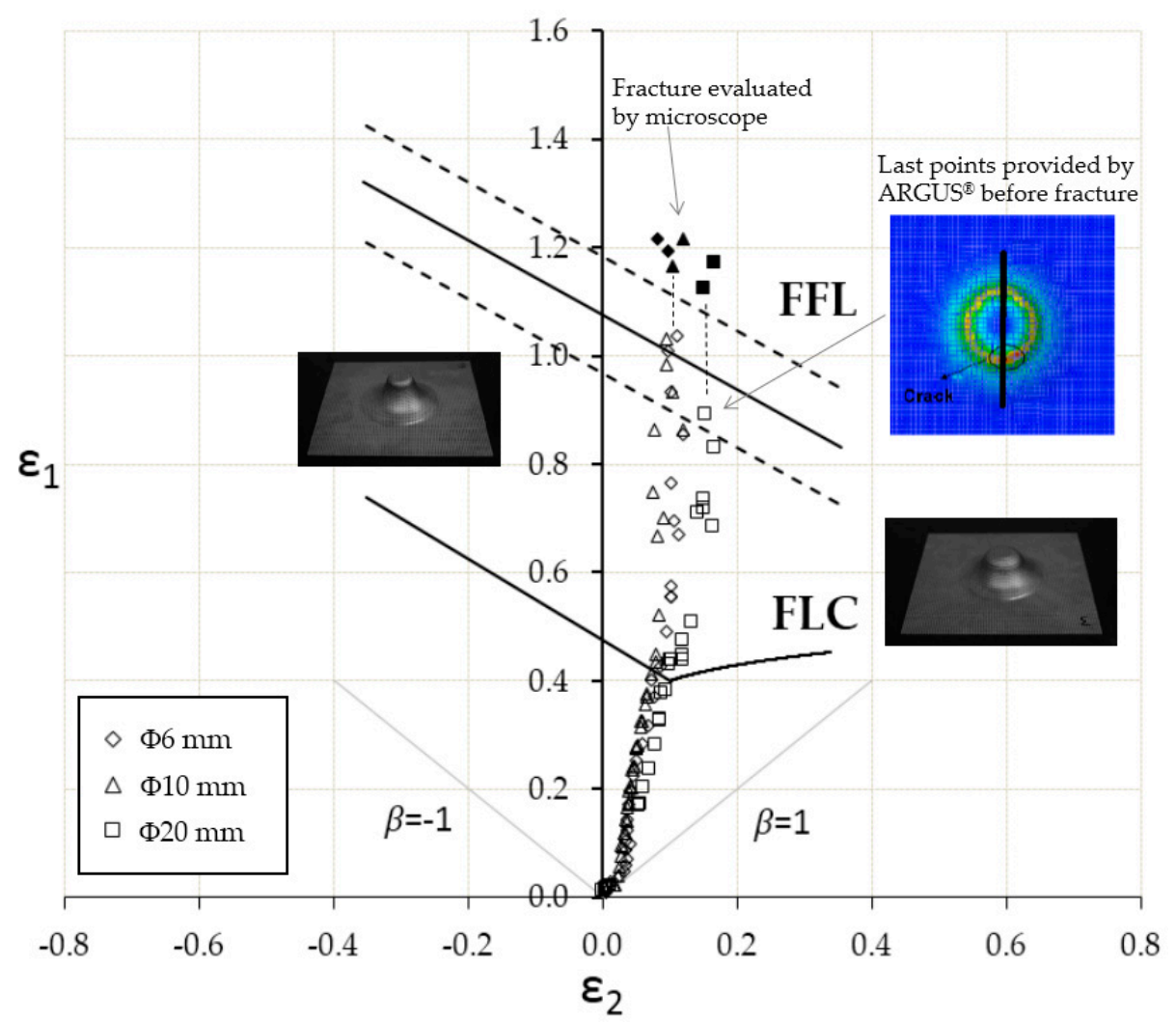

Figure 7. Principal strain state of the final testing part deformed by SPIF using tool diameters of $\Phi 20$, $\Phi 10$ and $\Phi 6 \mathrm{~mm}$ represented within the FLD of the material. 
In order to evaluate the failure mode and set the limit strain conditions at failure regarding the enhancement of formability attained in SPIF related to the $t_{0} / R$ ratio, the fracture zone was analyzed by microscope for the case of the smallest tool diameter of $\Phi 6 \mathrm{~mm}$. Figure 8 depicts the fractography at two sections of the final truncated cone. Section $\mathrm{A}-\mathrm{A}^{\prime}$ corresponds to the zone in which it seems that the crack is about to initiate whereas section $B^{-} B^{\prime}$ is placed within the crack line close to its end. On section $\mathrm{A}-\mathrm{A}^{\prime}$, a very incipient necking can be observed. On the contrary, section B-B' depicts a ductile fracture corresponding to a monotonous decrease of thickness until fracture. In both sections, the indentation produced by the tool can be easily observed. This indentation produced in certain SPIF conditions, mostly for small tool diameters, has been also evaluated using numerical tools [24].

This fractographic analysis led to the conclusion of the failure mode attained. In this sense, it seems that the part could be deformed plastically above the FLC presenting the cited monotonous decrease of thickness until ductile fracture took place, being only possible to register a much postponed incipient necking. Indeed, there was a competition between the bending effect represented by the $t_{0} / R$ ratio, which is the key factor for the increased formability in SPIF, and the tool indentation, that made this specific process to reach a threshold for the enhancement of formability for a tool diameter within the range of $10 \mathrm{~mm}$ to $6 \mathrm{~mm}$.
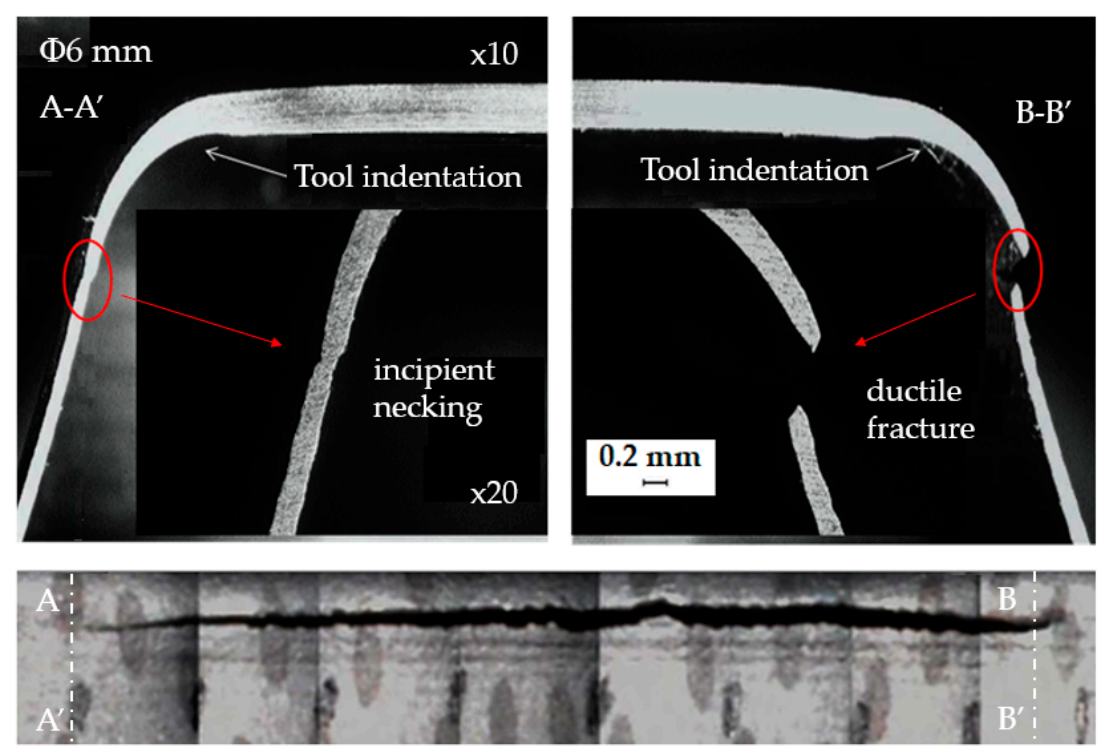

Figure 8. Fractography of the fracture zone at 2 sections for a tool diameter of $\Phi 6 \mathrm{~mm}$. Section A-A' corresponds to the crack initiation whereas section $\mathrm{B}^{-\mathrm{B}^{\prime}}$ is placed close to its end.

Moreover, related to the determination of the failure mode, it is important to establish how the crack initiates and develops in the SPIF process. With this aim, the online measurement of the forming force allowed triggering the actual depth in which failure was attained for every test (information shown in Table 2). Indeed, at the precise instant in which failure is reached, there is a drop down in the vertical force evolution that serves to stop the process and calibrate the final depth.

Some representative tests corresponding to a tool diameter of $\Phi 6 \mathrm{~mm}$ (marked in bold in Table 2) were selected to show the initiation and evolution of the crack. Figure 9 depicts the developed surfaces containing the crack corresponding to the 3 tests of a step down $0.5 \mathrm{~mm} /$ pass (Test 1 to 3 in Table 2) reaching final depths of 28.0, 28.5 and $28.0 \mathrm{~mm}$ and the second test (Test 2) corresponding to a step down of $0.2 \mathrm{~mm} /$ pass. Assuming the alternative movement of the tool for successive passes shown in Figure 3b, it is easy to understand the direction of the rightward crack evolution in 3 of the cases, and the leftward crack evolution in the case of reaching failure at a final depth of $28.5 \mathrm{~mm}$ (Test 2 corresponding to a step down of $0.5 \mathrm{~mm} /$ pass). This observation of the crack allows concluding that the crack initiates at a certain location where the limiting principal strains are reached (or the FFL in 
the case of total absence of necking) and it develops following the tool movements until the SPIF test is stopped. Notice the break with a certain angle of the crack straight line at the end location (marked with a circle in Test 2 corresponding to a step down of $0.5 \mathrm{~mm} /$ pass).

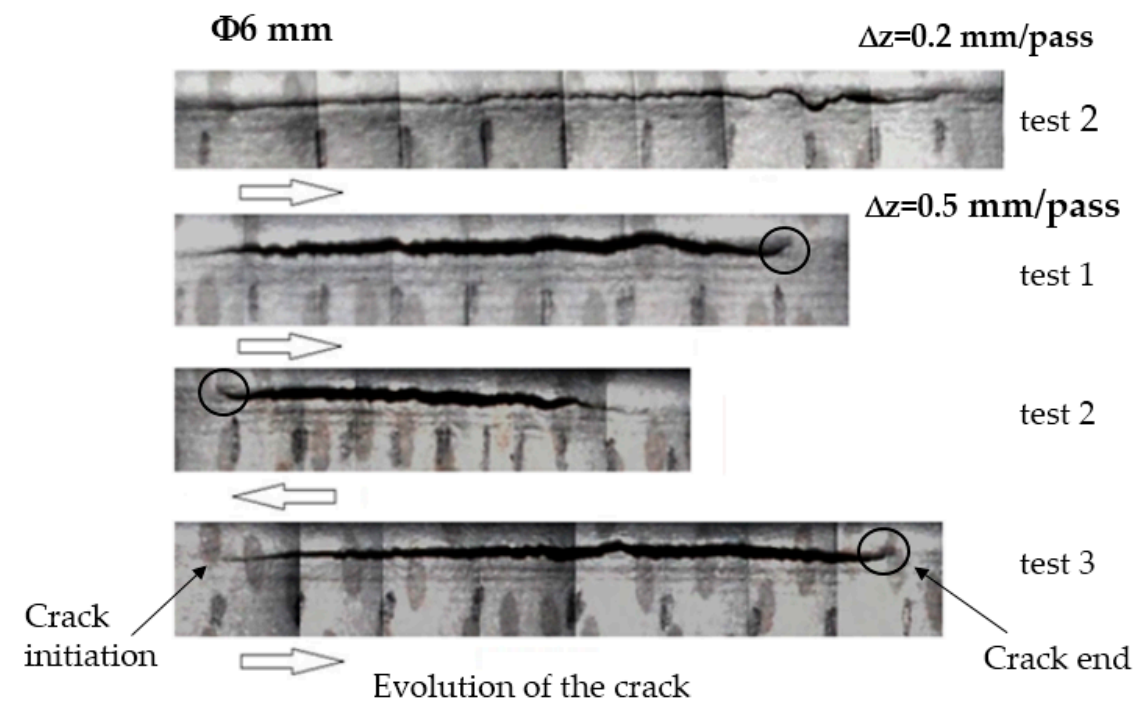

Figure 9. Evolution of the crack on the final testing part deformed by SPIF using a tool of $\Phi 6 \mathrm{~mm}$ diameter for some representative tests marked in bold in Table 2.

As far as the authors are aware, this observation of the crack initiation and development in SPIF has not been previously explained in the state of the art of ISF. Indeed, this is an important fact in order to choose the correct location for carrying out a fractographic analysis of the crack and determining the mode of failure as well as the average strains at fracture, as it was previously carried out in this section using the exposed methodology.

\subsection{Numerical Results}

The numerical values of the principal strain states in SPIF predicted from the FEA carried out using DEFORM ${ }^{\mathrm{TM}}-3 \mathrm{D}$ are compared with the experimental results presented in Figure 7 (step down of $0.5 \mathrm{~mm} /$ pass) within the FLD of the material for the tool diameters of $\Phi 20$ and $\Phi 10 \mathrm{~mm}$, i.e., including the transition from a theoretically necking controlled failure $(\Phi 20 \mathrm{~mm})$ to a failure mode of direct ductile fracture $(\Phi 10 \mathrm{~mm})$, as it was further discussed from the fractographic analysis carried out by the authors in [10].

In this regard, Figure 10 presents the numerical prediction of principal strain state at an average final depth corresponding to failure versus the experimental principal strains provided by ARGUS ${ }^{\circledR}$ as well as the strains at fracture evaluated as with the procedure exposed above, for a SPIF test using a tool of $\Phi 10 \mathrm{~mm}$ diameter and a step down of $0.5 \mathrm{~mm} /$ pass. As can be seen, the numerical prediction is in good agreement with the experimental results. Besides, the numerical results obtained using DEFORM $^{\mathrm{TM}}-3 \mathrm{D}$ allow obtaining a direct transition from stable plastic deformation towards ductile fracture in the absence of necking. Indeed, due to the discrete pattern of the initial grid of circle (of $1 \mathrm{~mm}$ diameter and separation of circle centers of $2 \mathrm{~mm}$ ) that, once the sheet is deformed into a final part, is analyzed using ARGUS $^{\circledR}$, there exists a gap between the highest value of major principal strain evaluated in the vicinity of the crack by ARGUS ${ }^{\circledR}$ and the fracture strains obtained at the very location of the crack. This lack of information has been covered by the numerical analysis carried out, allowing the authors to confirm the absence of necking in SPIF by FEA using the commercial software DEFORM $^{\mathrm{TM}}-3 \mathrm{D}$. 


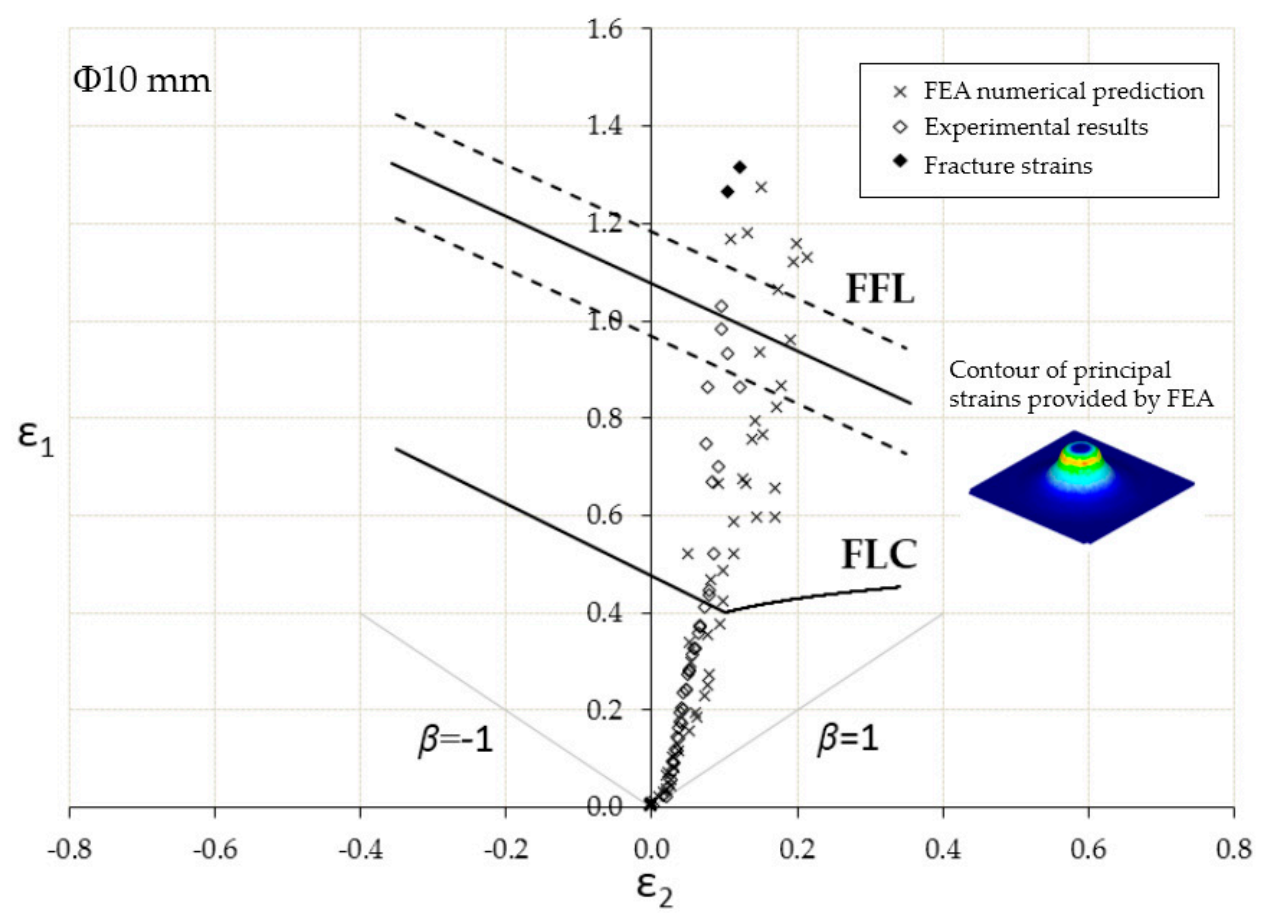

Figure 10. Numerical predictions versus experimental values of principal strains within the FLD of the material in the final testing part deformed by SPIF using a tool of $\Phi 10 \mathrm{~mm}$ diameter.

On the contrary, the mode of failure observed in SPIF of AISI 304 sheets using a tool of $\Phi 20 \mathrm{~mm}$ diameter was a necking-controlled failure, characterized by a postponed onset of necking (well above the FLC of the material) leading unstably towards ductile fracture (see [10] for further details). In this regard, Figure 11 presents the numerical predictions versus the experimental strains for this case. As can be seen, the numerical prediction is in good agreement with the experimental results, showing both results a gap of formability until the fracture strains, showing the dotted line the transition from the cited onset of postponed localized necking towards fracture.

Finally, the FEA allowed using ductile damage criteria in order to predict failure. In ISF processes, as it was discussed above, failure by direct ductile fracture might be attained within a range of process parameters depending on the material to be deformed. Besides, in most of usual testing geometries such as truncated cones and pyramids, fracture occurs under in-plane tension (see Figure 12a) corresponding to the mode I of fracture mechanics (see the recent unified vision of Martins et al. [25]). In these cases, the non-coupled damage criterion of McClintock [26] based on void growth applies as follows in Equation (3).

$$
D_{\text {crit }}=\int_{0}^{\bar{\varepsilon}} \frac{\sigma_{H}}{\bar{\sigma}} d \bar{\varepsilon}
$$

where the ratio of the hydrostatic $\left(\sigma_{H}\right)$ to the equivalent stress $(\bar{\sigma})$ represents the stress triaxiality and the critical damage can be calculated under Hill's anisotropic plasticity criterion with plane stress conditions as expressed in Equation (4).

$$
D_{\text {crit }}=\frac{(1+r)}{3}\left(\varepsilon_{1 f}+\varepsilon_{2 f}\right)
$$

where the average anisotropy coefficient $(r)$ is considered to be equal to 1 due to the simplification of considering an isotropic material in the FEA. Considering the average major and minor fracture strains calculated in SPIF this critical damage can be evaluated as $D_{\text {crit }}=0.8$. 


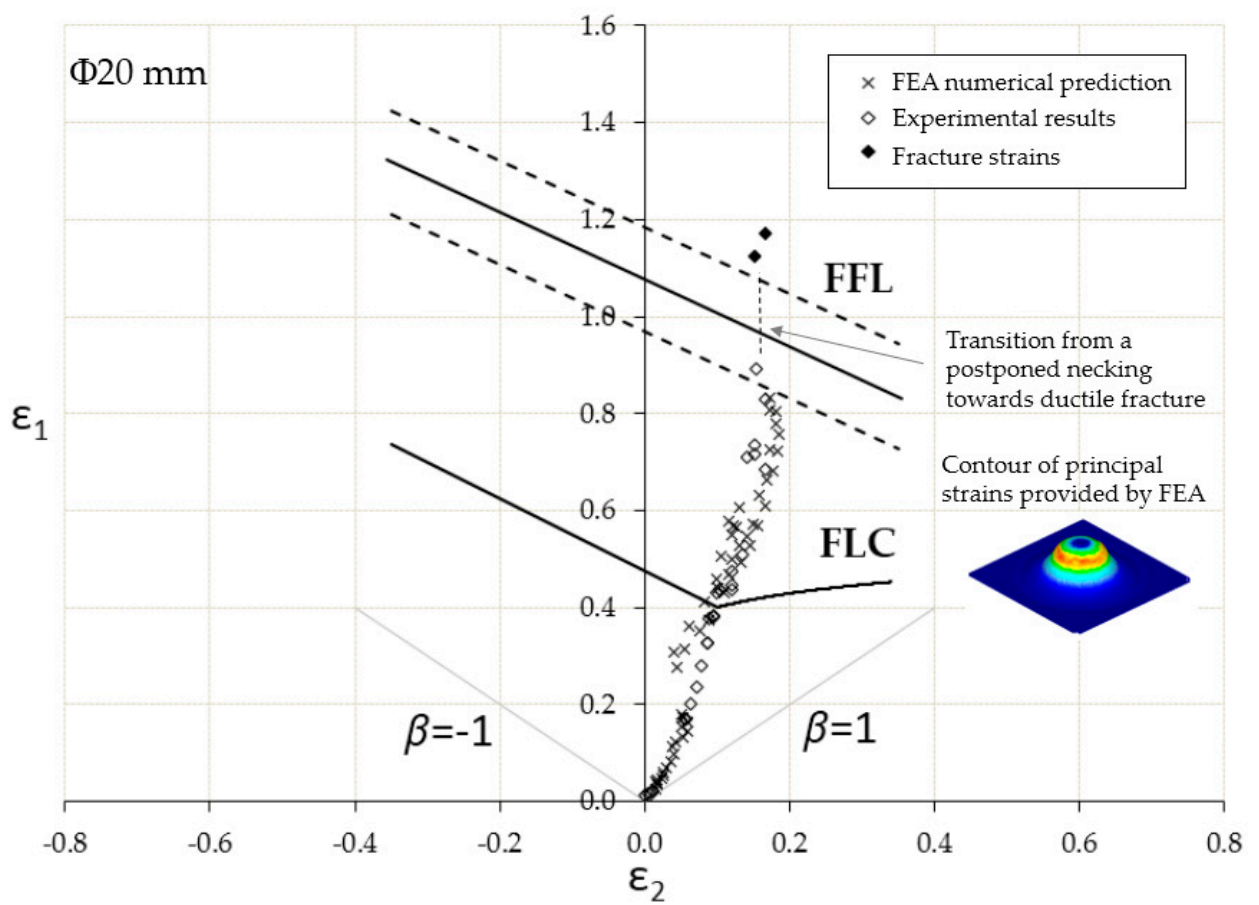

Figure 11. Numerical predictions versus experimental values of principal strains within the FLD of the material in the final testing part deformed by SPIF using a tool of $\Phi 20 \mathrm{~mm}$ diameter.

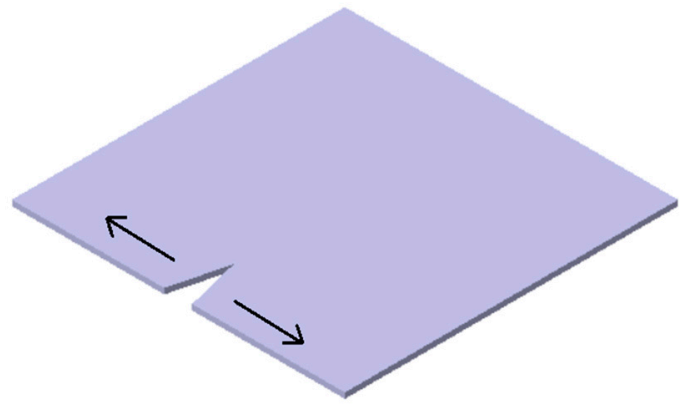

(a)

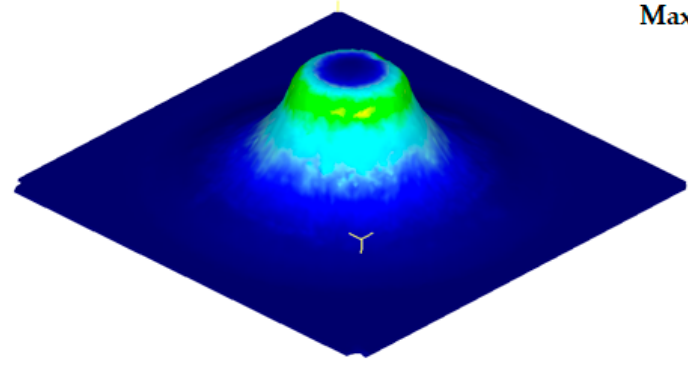

0.6

0.3

0.0

Figure 12. (a) Crack produced under In-plane tension corresponding to the Mode I and (b) Contour of accumulated damage using McClintock damage criterion for $\Phi 10 \mathrm{~mm}$ and step down $0.5 \mathrm{~mm} /$ pass.

Analyzing the accumulated damage in the case of a tool of $\Phi 10 \mathrm{~mm}$ diameter and a step down of $0.5 \mathrm{~mm} /$ pass, the case in which a direct transition from stable plastic deformation towards ductile fracture in the absence of necking was attained, the capacity of the numerical model for predicting failure by fracture in SPIF can be evaluated. Indeed, Figure $12 \mathrm{~b}$ depicts the accumulated ductile damage for a process stage corresponding to the final depth at failure.

As can be seen, the maximum value predicted for the accumulated damage was 0.888 , which is a reasonable prediction on the safe side, i.e., the predicted failure by fracture would have been attained in a previous stage of deformation corresponding to a smaller value of final depth.

To sum up, it must be notice that the relatively simple numerical model of the SPIF process presented in this research work allows evaluating formability and failure in incremental forming, providing fair predictions of the conditions upon which necking in SPIF is postponed or even suppressed. However, it is worth mentioning that there are very recent numerical works in ISF 
making use of more sophisticated modelling (considering material anisotropy, non-quadratic yield criteria, dynamic adaptive meshing, mixed hardening models, etc.) with the aim of reproducing more specific characteristic of the experimental procedure [24,27] or providing more accurate predictions for the onset of failure [28].

\section{Conclusions}

This research work revisits formability and failure of AISI304 sheets deformed by single point incremental forming. Formability in SPIF has been compared to conventional testing conditions, including Nakazima and stretch-bending. With this purpose, experimentation in SPIF and stretch-bending has been carried out and a Finite Element modelling of the SPIF process has been performed. The results obtained contributed to the current state of the art in SPIF as follows:

- The limit strains in SPIF have been experimentally evaluated through the competition between the bending effect represented by the $t_{0} / R$ ratio and the tool indentation, setting a threshold for the enhancement of formability for a tool diameter within the range of $10 \mathrm{~mm}$ to $6 \mathrm{~mm}$.

- The crack initiation and development in SPIF has been triggered, this analysis being crucial for determining the correct location to analyze the mode of failure and fracture strains.

- The FEA performed allowed the numerical establishment of the conditions upon which necking in SPIF was suppressed, the mode of failure being direct ductile fracture, and proved to be an useful tool providing fair and safe failure predictions by using the McClintock damage criterion.

Acknowledgments: The authors would like to express their gratitude for the funding received from the University of Girona (MPCUdG2016/036) and the Spanish Ministry of Education through the major grants DPI2015-64047-R and DPI2016-77156-R. The third author acknowledges gratefully the support from the Spanish doctoral grant FPU12/05402. The collaborations of BsC Álvaro Fernández Díaz and BsC José Manuel Carmona Romero are also greatly acknowledged.

Author Contributions: Gabriel Centeno, Isabel Bagudanch and María Luisa Garcia-Romeu designed the experimental plan and conducted the SPIF tests. Andrés Jesús Martinez-Donaire and Carpóforo Vallellano carried out the stretch-Bending and Nakazima tests. Domingo Morales-Palma and Gabriel Centeno performed the numerical simulations. All the authors contributed in the interpretation of the results obtained. The paper was written by Gabriel Centeno.

Conflicts of Interest: The authors declare no conflict of interest.

\section{References}

1. Leszak, E. Apparatus and Process for Incremental Dieless Forming. U.S. Patent 3,342,051, 19 September 1967.

2. Berghahn, W.G.; Murray, G.F. Method of Dieless forming Surfaces of Revolution. U.S. Patent 3,316,745, 2 May 1967.

3. Emmens, W.C.; Van den Boogaard, A.H. The technology of incremental sheet forming-A brief review of the history. J. Mater. Process. Technol. 2010, 210, 981-997. [CrossRef]

4. Mason, B. Sheet Metal Forming for Small Batches. Bachelor's Thesis, University of Nottingham, Nottingham, UK, 1978.

5. Mason, B.; Appleton, E. Sheet metal forming for small batches using sacrificial tooling. In Proceedings of the 3rd International Conference on Rotary Metalworking, Kyoto, Japan, 8-10 September 1984; pp. 495-511.

6. Centeno, G.; Martínez-Donaire, A.J.; Morales-Palma, D.; Vallellano, C.; Martins, P.A.F. Novel experimental techniques for the determination of the forming limits at necking and fracture. In Materials Forming and Machining; Davim, P., Ed.; Woodhead Publishing: Cambridge, UK, 2016; pp. 1-24.

7. Emmens, W.C.; Van den Boogaard, A.H. An overview of stabilizing deformation mechanisms in incremental sheet forming. J. Mater. Process. Technol. 2009, 209, 3688-3695. [CrossRef]

8. Silva, M.B.; Nielsen, P.S.; Bay, N.; Martins, P.A.F. Failure mechanisms in single point incremental forming of metals. Int. J. Adv. Manuf. Technol. 2011, 56, 893-903. [CrossRef]

9. Madeira, T.; Silva, C.M.A.; Silva, M.B.; Martins, P.A.F. Failure in single point incremental forming. Int. J. Adv. Manuf. Technol. 2015, 80, 1471-1479. [CrossRef] 
10. Centeno, G.; Bagudanch, I.; Martínez-Donaire, A.J.; Garcia-Romeu, M.L.; Vallellano, C. Critical analysis of necking and fracture limit strains and forming forces in single-point incremental forming. Mater. Des. 2014, 63, 20-29. [CrossRef]

11. Isik, A.K.; Silva, M.B.; Tekkaya, A.E.; Martins, P.A.F. Formability limits by fracture in sheet metal forming. J. Mater. Process. Technol. 2014, 214, 1557-1565. [CrossRef]

12. Soeiro, J.M.C.; Silva, C.M.A.; Silva, M.B.; Martins, P.A.F. Revisiting the formability limits by fracture in sheet metal forming. J. Mater. Process. Technol. 2009, 217, 184-192. [CrossRef]

13. International Standard ISO 12004-2:2008. Metallic Materials-Sheet and Strip-Determination of Forming Limit Curves, Part 2: Determination of Forming Limit Curves in the Laboratory; International Organisation for Standardization: Geneva, Switzerland, 2008.

14. Martínez-Donaire, A.J.; García-Lomas, F.J.; Vallellano, C. New approaches to detect the onset of localised necking in sheets under through-thickness strain gradients. Mater. Des. 2014, 57, 135-145. [CrossRef]

15. Atkins, A.G. Fracture in forming. J. Mater. Process. Technol. 1996, 56, 609-618. [CrossRef]

16. Centeno, G.; Morales-Palma, D.; Gonzalez-Perez-Somarriba, B.; Bagudanch, I.; Egea-Guerrero, J.J.; Gonzalez-Perez, L.M.; Garcia-Romeu, M.L.; Vallellano, C. A functional methodology on the manufacturing of customized polymeric cranial prostheses from CAT using SPIF. Rapid Prototyp. J. 2017, 23, 771-780. [CrossRef]

17. Bagudanch, I.; Centeno, G.; Garcia-Romeu, M.L.; Vallellano, C. Revisiting formability and failure of polymeric sheets deformed by Single Point Incremental Forming. Polym. Degrad. Stab. 2017, 144, 366-377. [CrossRef]

18. Centeno, G.; Silva, M.B.; Alves, L.M.; Vallellano, C.; Martins, P.A.F. Towards the characterization of fracture in thin-walled tube forming. Int. J. Mech. Sci. 2016, 119, 12-22. [CrossRef]

19. Arısoy, Y.M.; Guo, C.; Kaftanoğlu, B.; Özel, T. Investigations on microstructural changes in machining of Inconel 100 alloy using face turning experiments and 3D finite element simulations. Int. J. Mech. Sci. 2016, 107, 80-92. [CrossRef]

20. Amigo, F.J.; Camacho, A.M. Reduction of induced central damage in cold extrusion of dual-phase steel DP800 using double-pass dies. Metals 2017, 7, 335. [CrossRef]

21. Palaniswamy, H.; Ngaile, G.; Altan, T. Finite element simulation of magnesium alloy sheet forming at elevated temperatures. J. Mater. Process. Technol. 2004, 146, 56-60. [CrossRef]

22. Lee, Y.S.; Kwon, Y.N.; Kang, S.H.; Kim, S.W.; Lee, J.H. Forming limit of AZ31 alloy sheet and strain rate on warm sheet metal forming. J. Mater. Process. Technol. 2008, 201, 431-435. [CrossRef]

23. Wilson, D.V.; Mirshams, A.R.; Roberts, W.T. An experimental study of the effect of sheet thickness and grain size on limit-strains in biaxial stretching. Int. J. Mech. Sci. 1983, 25, 859-870. [CrossRef]

24. Neto, D.M.; Martins, J.M.P.; Oliveira, M.C.; Menezes, L.F.; Alves, J.L. Evaluation of strain and stress states in the single point incremental forming process. Int. J. Adv. Manuf. Technol. 2016, 85, 521-534. [CrossRef]

25. Martins, P.A.F.; Bay, N.; Tekkaya, A.E.; Atkins, A.G. Characterization of fracture loci in metal forming. Int. J. Mech. Sci. 2014, 83, 112-123. [CrossRef]

26. McClintock, F.A. A criterion for ductile fracture by the growth of holes. J. Appl. Mech. 1968, 35, 363-371. [CrossRef]

27. Esmaeilpoura, R.; Kima, H.; Park, T.; Pourboghratab, F.; Mohammed, B. Comparison of 3D yield functions for finite element simulation of single point incremental forming (SPIF) of aluminum 7075. Int. J. Mech. Sci. 2017, 133, 544-554. [CrossRef]

28. Mirnia, M.J.; Shamsari, M. Numerical prediction of failure in single point incremental forming using a phenomenological ductile fracture criterion. J. Mater. Process. Technol. 2017, 244, 17-43. [CrossRef]

(C) 2017 by the authors. Licensee MDPI, Basel, Switzerland. This article is an open access article distributed under the terms and conditions of the Creative Commons Attribution (CC BY) license (http://creativecommons.org/licenses/by/4.0/). 